Williams, T.K., McIntosh, R.W., \& Russell, W.B. Equity in Distance Education During COVID-19

\title{
Equity in Distance Education During COVID-19
}

\author{
Tamika K. Williams, Robert W. McIntosh \& William B. Russell III* \\ University of Central Florida \\ *Corresponding Author: russell@ucf.edu \\ Received : 2021-01-26 \\ Revised : 2021-04-02 \\ Accepted : 2021-04-29 \\ $10.46303 /$ ressat.2021.1
} How to cite this paper: Williams, T.K., Mclntosh, R.W., \& Russell, W.B. (2021). Equity in distance education during COVID-19. Research in
Social Sciences and Technology, 6(1), 1-24. https://doi.org/10.46303/ressat.2021.1

This is an Open Access article distributed under the terms of the Creative Commons Attribution 4.0 International license (https://creativecommons.org/licenses/by/4.0/).

\begin{abstract}
This study uses the phenomenological approach to qualitative research to explore the COVID19 distance learning experiences of educators who served students with varying digital access and efficacy. The researchers analyzed survey data collected from 13 educators that was used to guide a focus group discussion with 11 educators. The participants reported that although their students experienced inequities in both digital access and digital efficacy, there was a greater issue with access to technology. The study also found that educators dealt with digital inequities by putting in extra work and shifting their mindsets. Educators also reported a desire to maintain the reforms that helped their students.
\end{abstract}

Keywords: COVID-19, digital divide, educational technology, distance education, educational inequity

\section{Introduction}

The COVID-19 pandemic forced school districts, schools, and teachers to mobilize in order to deal with the digital inequities that have existed for decades. At the beginning stages of technological advances in education, the so-called digital divide related more to access to technology and equipment. There was unequal access to technology that gave some students advantages over others. However, current data suggests that the divide has shifted (Hall et al., 2020; Kaden, 2020; Lynch, 2020; Reinhart et al., 2011; Sandvik, 2020; Tang \& Bao, 2020). Even when access to technology is equal, inequities persist because some students and teachers do 
Williams, T.K., McIntosh, R.W., \& Russell, W.B. Equity in Distance Education During COVID-19

not have the necessary training and skills to take advantage of technological resources. Due to the evolving nature of the pandemic, data on this phenomenon is limited, and interpretations are fluid. However, there are patterns in the available data in regard to the impact of technology and training challenges on educational equity. Reports show that educators took actions to close the digital divide during the pandemic that included providing resources and training (Kaden, 2020; Kalimullina et al., 2021; Lynch, 2020; Rhim \& Han, 2020; Swarts, 2020; Tadeu et al., 2019; Whittle et al., 2020). They also implemented new teaching methods designed to preserve the sense of community during distance learning.

\section{Purpose}

COVID-19 and the educational response to it affected all students and teachers. Thus, it is important to consider whether and how digital inequities are affecting students and teachers. The purpose of this research is to add to our understanding of these effects through the collection and interpretation of self-reported teacher views. The following questions guided the study:

1. How have teachers, schools, and districts responded to the closing of schools as a result of the COVID-19 pandemic?

2. Did they consider the digital divide in their responses to mitigate the instructional consequences of the pandemic?

3. Have teachers seen evidence of a digital divide when online learning was implemented?

4. Do teachers feel that their technology preparation (or lack) influenced the quality of their and their students' experience?

5. Will any changes or improvements be continued after COVID?

\section{Literature Review}

\section{Reckoning and Awareness}

The COVID-19 pandemic forced teachers and educational leaders to reckon with existing digital inequities that some were not even aware existed. Because distance learning was the main and sometimes only learning platform at the beginning of the COVID lockdown, 
Williams, T.K., McIntosh, R.W., \& Russell, W.B. Equity in Distance Education During COVID-19

it highlighted digital divide issues, but lessons learned should be carried over to benefit students and achieve educational equity (Hall et al., 2020). Kaden (2020) found that the forced response to the pandemic revealed what was missing when "going digital" and what support and resources were necessary to make sure schools could still be effective and run efficiently. The teacher in Kaden's case study became aware of the challenges his most vulnerable students had to deal with, challenges that were only exacerbated by the pandemic. He had homeless and transient students that he lost contact with and special needs students that he could not properly support. The pandemic also revealed the skills this teacher was missing, some skills he did not know he even needed. Hall et al. (2020) found that the pre-service teachers in their study who analyzed digital access data became aware of the unequal access to technology and technology training and the systemic racial inequities that contributed to the digital divide. However, these future teachers recognized the potential for technology to truly improve opportunities if inequities are considered and addressed.

This growing awareness led to improvements in practice and procedures, even if temporarily. Rhim and Han (2020) say the sudden and involuntary move to online learning pressed teachers to adopt new teaching methods and to learn new technology. Not only did teachers have to acquire technical skills, but they also had to learn new methods for delivering lessons. Teachers could not just take their face-to-face lessons and post them on their district's digital platform (Godsey, 2020; Han, 2020, Kaden, 2020; \& Rhim). Whittle et al. (2020) say the experience of COVID-19 revealed the need for an educational framework to guide and support remote instruction that is necessitated by crisis situations. These researchers proposed their emergency remote teaching environments (ERTE) framework, anticipating future emergency situations.

Even though COVID-19 was a temporary crisis situation, educators and educational researchers found the need to retain the lessons gleaned from the experience. The pre-service teachers in Hall et al.'s study expressed the need to recognize privilege and use that recognition to help marginalized students (2020). The researchers in the study urged teacher educators to continue exposing future teachers to inequities after emergency distance learning ends because the inequities will still be there. School districts had to create new educational models 
Williams, T.K., McIntosh, R.W., \& Russell, W.B. Equity in Distance Education During COVID-19

that were flexible and accessible in order to facilitate continued learning in the midst of a global crisis. Parents, students, and the world economy depended on it (Kaden, 2020). Some new models may be more effective than the pre-COVID one and should not be abandoned once the crisis ends (Kaden, 2020; Sandvik, 2020). For example, a distance learning model can allow for more flexibility, cost-effectiveness, and independence. Kaden (2020) argues that distance learning should not be designed to replace or mimic traditional in-person learning but should add to the body of pedagogical knowledge.

\section{Access and Efficacy}

Researchers describe the digital divide as having at least two components, with the first focused on access to technology and the internet and the second focused on the efficacy of its use (Hargittai, 2001; Reinhart et al., 2011; Tang \& Bao 2020). Traditionally, the first level digital divide focuses on those who have access and those who don't, sometimes called the "haves" and the "have nots." The Pew Research Center (2020) reported that in the United States, the "have nots" are on the decline as of February 2019, with 90\% of U.S. adults using the internet and $71 \%$ with high-speed broadband internet access at home. That does not mean that we should dismiss the first level of the digital divide because it remains a reality, particularly for rural and lower socioeconomic status (SES) Americans (Anderson \& Kumar, 2020; Perrin, 2020). Additionally, the Pew Research Center study focused on adults and did not communicate the full story when considering school-age children. To overcome the first level digital divide during the emergency remote teaching setting created by COVID-19, schools and school districts have distributed technology for students that did not have access at home and often needed to provide or support internet access at home as well. Unfortunately, schools in low SES areas also tend to have reduced technology infrastructure to support the needs of their students and community during times of crisis and school closures (Sayer \& Braun, 2020).

The second level of the digital divide transitions from access to technology and the internet to the efficacy of its use. Another way to consider this level of the digital divide is to consider the difference between those who consume information from the internet and those who produce it (Hargittai \& Walejko, 2008; Tang \& Bao 2020). The difference between these two groups focuses heavily on information and communication technologies (ICT) skills and 
Williams, T.K., McIntosh, R.W., \& Russell, W.B. Equity in Distance Education During COVID-19

education, and like technology access, this divide tends to be bound with SES (Tang \& Bao, 2020). Another factor of the second-level digital divide comes in the form of technology used, with an increasing number of Americans relying on smartphones to access and interact with the internet (Anderson, 2020). Smartphones do not prevent users from overcoming the second level of the digital divide, but they do reduce their access to programs and applications that are often used to generate and create content online.

It is critical to understand that both students and teachers find themselves being influenced by the digital divide. Inequities in teachers' understanding and use of ICTs must be considered when measuring the impact of school closures and emergency remote teaching (Godsey, 2020). Trust and Whalen (2020) found that teachers were often relying on informal networks or self-directed learning in order to overcome the difficulties transitioning from the traditional school-based modality to the emergency remote teaching setting required during COVID-19. Ongoing training and professional development for teachers in ICTs and distance education are needed in order for teachers to effectively transition instruction during crises (Hall et al., 2020; Lynch 2020; Peterson et al., 2020; Tang \& Bao, 2020; Trust \& Whalen, 2020). School-based embedded technology facilitators are one way to provide informal and ongoing training that teachers need as technology changes and demand shifts based on current circumstances (Reinhart et al., 2011).

\section{Connection and Community Building}

Because of the isolation and separation of distance learning, much of the most effective transformations of methods and strategies during the pandemic related to communication and community building (Bertacco, 2020; Godsey, 2020; Kaden, 2020; Lynch, 2020; Rhim \& Han, 2020; Sayer \& Braun, 2020; Whittle et al., 2020). This is especially the case for students with the greatest need, such as those students who have disabilities, are living in poverty, or are from marginalized groups (Bertacco, 2020; Godsey, 2020; Kaden, 2020; Lynch, 2020). Teachers cannot just take their classroom and lessons and move them online without accommodating for the loss of face-to-face connection (Bertacco, 2020; Godsey, 2020; Rhim \& Han, 2020). Lynch (2020) found from her survey of best practices around the world that it is important to 
Williams, T.K., McIntosh, R.W., \& Russell, W.B. Equity in Distance Education During COVID-19

create shared spaces for students that their emotional needs can be met along with their educational needs.

It is important for the teacher to maintain a personal connection to students and parents, which can be more challenging but is even more essential with the most vulnerable students and families (Godsey, 2020; Kaden, 2020). Godsey (2020) points out that not all students have the advantage of an educated parent at home, access to resources, stable internet, or even a safe space to study. Whittle et al.'s (2020) ERTE framework highlights the social role of the teacher to support not only the students but their parents, who must now take on the role of teaching assistant. Teachers should be in regular communication with parents and students. This role is closely related to ERTE's feedback dimension, as teachers need to provide quick assessment feedback. Teachers in Sandvik's (2020) survey reported that they learned the importance of providing feedback to students in various ways. Zoom and other online meeting platforms have become teachers' and students' best friend and worst enemy. Teachers report that there can be too much screen time and information overload (Lynch, 2020; Sandvik, 2020). However, Bertacco (2020) found that teachers should use the time on screen to engage with students. Godsey (2020) says some synchronous meeting time is necessary to build a connection. While maintaining the necessary contact with families is necessary, it can add to teachers' workload (Kaden, 2020; Sandvik, 2020).

Students need to be social and craved a connection with peers during the pandemic (Kaden, 2020; Rhim \& Han, 2020; Whittle et al., 2020). Whittle et al. (2020) highlight the critical social component of learning; students who are limited to online learning have a better experience when they have opportunities to interact with other students. Incorporating tools such as message boards, breakout rooms, games can allow for interaction, collaboration, and community building (Bertacco, 2020; Godsey, 2020; Lynch, 2020). Bertacco (2020) warns that the learning context is what is most affected during the COVID-imposed remote learning and must be addressed to make sure educators reach all students.

It is also important and beneficial for teachers to remember their needs during emergency remote learning (Godsey, 2020). Teachers also experienced COVID-19 differently due to inequities (Kaden, 2020; Reinhart et al., 2011; Sandvik, 2020; Tang \& Bao, 2020). 
Williams, T.K., McIntosh, R.W., \& Russell, W.B. Equity in Distance Education During COVID-19

Collaboration among teachers and the sharing of knowledge and resources is vitally important (Godsey, 2020).

The global pandemic that entered the United States in the spring of 2020 forced educators to do what educators have been talking about doing for decades: to revolutionize schools to meet the needs of a diverse population of students. The experience of forced distance learning highlighted the technological divides among students and forced school systems to close those divides by providing access and addressing technological efficacy issues. The work to close the digital gap revealed deeper sociological issues (Kaden, 2020; Sayer \& Braun; 2020; Tang \& Bao, 2020). A byproduct of attending to the technological gap was bringing attention to student needs that went beyond providing laptops and internet access. The pandemic connected the home and school environment in ways that educators found challenging but informative and transformational. Teachers, school leaders, and educational researchers concluded that the lessons learned need to be retained and that the reforms need to be permanent (Hall et al., 2020; Lynch, 2020; Whittle et al., 2020). It is important to study and reflect on this pandemic through the eyes of the educators on the front lines of what might be an educational revolution. This study examines the experiences and reflections of current educators who serve in different capacities in a school district in the Southeastern United States.

\section{Data and Method}

We used the phenomenological approach to qualitative research for this study to describe the experiences of educators who served students with differing experiences and needs during the COVID-19 pandemic. After the Institutional Review Board approved the study, we began recruiting participants to take an anonymous survey about their experiences and perceptions. Potential participants were advised of their rights to participate and/or decline participation in the anonymous survey and/or a focus group discussion conducted through the Zoom virtual meeting platform. Those participants who gave consent were sent an anonymous link to the survey that consisted of both Likert-type questions and open-response questions. Those participants who indicated their willingness to also participate in the focus group discussion were sent invitations to a follow-up Zoom meeting. They were given the option to 
Williams, T.K., McIntosh, R.W., \& Russell, W.B. Equity in Distance Education During COVID-19

change their display names and turn off their videos to maintain anonymity. We also use pseudonyms in our report to protect the identities of our participants.

\section{Participants}

Seven teachers, two counselors, and four administrators took the survey $(N=13)$. Three administrators, two counselors, and six teachers participated in the focus group discussion $(\mathrm{N}=11)$ (see Table 1). Elementary, middle, and high school levels were represented in both the survey and focus group data.

\section{Table 1}

Focus Group Participants

\begin{tabular}{llll}
\hline Pseudonym & Gender & Ethnicity & Role \\
\hline Joy & Female & Black & Administrator \\
Angie & Female & White & Teacher \\
Reggie & Male & Black & Teacher \\
Frank & Male & White & Administrator \\
Harmony & Female & Black & Administrator \\
Kendra & Female & Black & Teacher \\
Chris & Male & White & Teacher \\
Josh & Male & White & Teacher \\
Sylvia & Female & Hispanic & Teacher \\
Shonda & Female & Black & Counselor \\
Denise & Female & Black & Counselor \\
\hline
\end{tabular}

\section{Data Sources}

The survey instrument consisted of 10 background questions, 20 Likert-type questions, and four open-response questions (Appendix A). There were four categories of questions for the survey related to the teacher and district response to the pandemic, consideration of the 
Williams, T.K., McIntosh, R.W., \& Russell, W.B. Equity in Distance Education During COVID-19

digital divide in that response, evidence of a digital divide, and educators' technological training. The questions were designed based on evidence from existing research. We used the survey responses to get a general understanding of the experiences and perceptions of educators in relation to educational equity during the pandemic. We used data from the educator survey to inform and guide our two-hour focus group discussion (Silverman, 2017). We triangulated the data by interviewing multiple participants who serve in varying capacities and using multiple data collection methods, including the survey and focus group discussion (Kozleski, 2017). The focus group discussion provided for participant verification and feedback to support trustworthiness (Kozleski, 2017). Data analysis for this report centers on the focus group discussion.

\section{Data Analysis}

We used the phenomenological approach to analysis the data (Creswell \& Poth, 2018). The overall data analysis process is summarized in Figure 1. First, we reviewed the participants' background information to get an overall idea of the varying roles, characteristics, and contexts of the participants. We did not intend to perform any quantitative interpretive analysis of the data. Next, we studied the responses to the Likert-style questions to explore educators' impressions and experiences of education during the pandemic. To do this, we formed topic categories, synthesized categories into themes, and compared themes to themes in the existing literature. We used our analysis of the educators' expressions in the survey to determine what was significant about their experience and what should be discussed further.

From this interpretation, we formed the basis of our focus group discussion, which was guided by twelve discussion questions (Appendix B). We began analysis of the focus group discussion with memoing, which involved getting a general overview of the discussion, and taking notes. Next, we created a table to form categories. For the category formation process, we reviewed the transcripts and segmented it according to question. We made notes as topics came up in the discussion (see Figure 2). We used the topics as column headings in the table. For each question, we wrote details under the heading about what was said about the topic and by whom. We then compared notes and reviewed the categories for patterns. We 
synthesized the categories into themes. Finally, we went back to the transcripts to verify themes by using a color-coded highlighting process.

\section{Figure 1}

Summary of Data Analysis Process

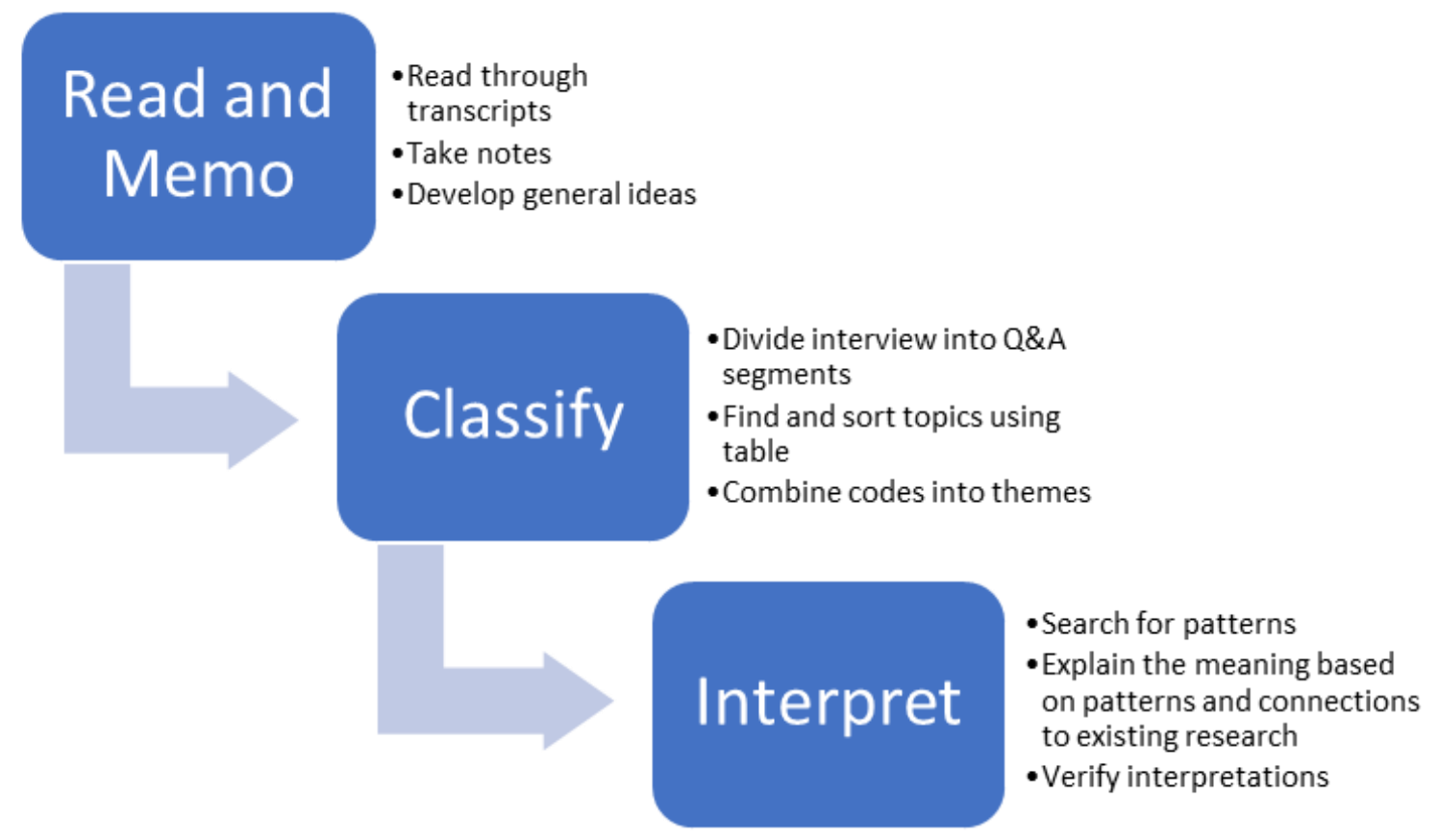

Figure 2

Focus Group Discussion Topic Categories
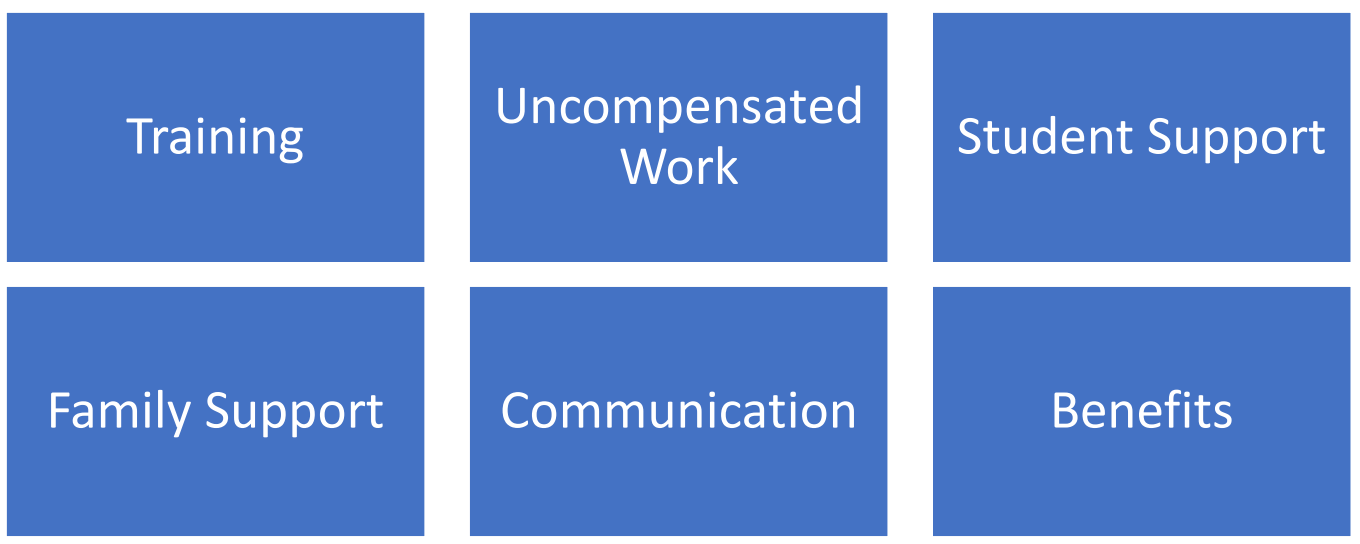
Williams, T.K., McIntosh, R.W., \& Russell, W.B. Equity in Distance Education During COVID-19

\section{Results}

Responses from the 20-question Likert survey mostly supported what has been found by other researchers on the topic. Students and families from high needs populations such as those who spoke English as a second language, those with varying exceptionalities, those from minority groups, and those who qualify for free or reduced lunch struggled due to technology, economic, and communications issues. Teachers and staff were overwhelmed but worked hard to overcome the issues their students faced. One major conflict with the existing research is that teachers reported access to technology as more of a problem than its efficacy. Even though the district provided laptops for students who qualified for free or reduced lunch, those students were often disrupted by connection issues such as poor WiFi signals or problems with the video conference application. The educators' responses also did not emphasize the use of collaboration as much as the existing literature would suggest.

Based on the survey responses, we created the twelve discussion questions to discover how the educators' experience might be applied to improve educational practice in a similar crisis and in general. We wanted to find out more about what the educators were doing to mitigate the challenges they and their students faced and to support their most vulnerable students. What emerged from the focus group discussion were three themes: (a) when educators put in extra work, students benefited, (b) the pandemic forced a shift in mindset that inspired new behaviors and resulted in positively surprising outcomes, and (c) teachers want the lessons learned from the experience to lead to lasting change.

\section{Extra Work Paid Off}

The discussion showed that although educators were overwhelmed and exhausted with the amount of uncompensated time and energy they had to put in during the pandemic, the investment of extra time and energy resulted in positive outcomes for them and their students. Many teachers, counselors, and administrators took the initiative to attend summer workshops and to complete self-taught training sessions. During the interview Angie explained, "Over the summer, I did like, 55 different workshops and all the workshops were online geared." In Angie's school district, the summer trainings offered through the district were often taught by district-based employees, such as other teachers. Chris was one of the teachers that led 
Williams, T.K., McIntosh, R.W., \& Russell, W.B. Equity in Distance Education During COVID-19

professional development over the summer. He designed a training that focused on the use of digital discussion boards to make discussions engaging for students. For the teachers, the summer workshops better equipped them to support their students.

Teachers spent hours outside of work hours troubleshooting technical issues, counseling stressed students and parents, answering emails, and creating engaging and innovative lessons. Harmony, an administrator, found that she and her staff basically needed to train the parents on how to work with the online tools including the gradebook and the virtual learning environment. This was often done in case-by-case situations with administrators throughout the district, instead of through a dedicated program or workshop. Chris also described spending hours on the phone with parents, "walking them through the gradebook because they never had to check the grade books themselves before." In comparison, Angie found that often the parents, grandparents, or guardians would give the teachers a cell phone number to contact students directly. This way the teachers could, "just talk to them ourselves and say, 'Hey, what are you doing? How can I help you?'” (Angie). Josh and other teachers in his team decided that they needed to be the tech support for their students and parents. They even created videos to quickly share some of the more common how-to situations. This was in addition to their actual instructional roles.

Educators discovered that practicing digital tools and allowing students and parents to use digital tools lessened stress. They discovered that incorporating community building in lesson plans worked for students who were isolated and lost in distance learning. They found out that breakout rooms created safe spaces for some students, "because sometimes they don't feel comfortable sharing in whole group" (Harmony). This district used split classrooms where some students watched the teacher online while other students were physically in the room with the teacher. Reggie would pair students up, online with in-person. He rationalized his effort, "it's kind of like forcing conversation because if it doesn't happen the online kids will turn the screen off and not participate at all." Educators found ways to make this a better experience for their students.

\section{Mindset Shift}


Williams, T.K., McIntosh, R.W., \& Russell, W.B. Equity in Distance Education During COVID-19

The pandemic forced educators to rethink, reprioritize, and reevaluate their habits and behaviors. They did things they had never done because they had to. For example, Reggie and his peers synchronized their lesson plans. Josh's school required teachers to standardize their virtual classroom homepages to improve ease of use for the students and parents. These changes created benefits for teachers and students.

From the focus group we learned that, when used properly, the online tools helped to remove the divide between home and school. The pandemic pushed parents to engage with learning platforms that have been in use for years. In Chris's school district they introduced the learning management system, Canvas, county-wide five years ago, "I spent several hours on the phone with parents who needed help understanding the technology like the learning management system" (Chris). These applications have features designed to give parents a window into the classroom, but many never knew their purpose or how to use them. Kendra described how it was possible to address issues quickly, "if something wasn't going well by the end of the day, I can quickly say, 'Hey, can you get your mom or can you get your Grandma.' You know, so issues were fixed instantly."

The administrators in the focus group recounted how the pandemic encouraged the teachers to challenge themselves in new ways. Frank described how the teachers who invested the effort to design lesson plans that use the digital tools in an engaging way are finding greater success in this environment. He said, "those are the classrooms that we noticed have higher engagement, higher grades, and less disparity." Harmony explained how a different set of teachers are becoming leaders on campus. These teachers often include the younger and newer teachers, "I've seen where new teachers because they're young and they're used to this platform anyway, where they become tutors to veteran teachers" (Harmony). The pandemic is forcing the school system to embrace technology and to become more flexible to meet the needs of the students.

Educators described how they paid attention to their students in a different way since the beginning of the COVID-19 pandemic. Reggie's big take-away was realizing the complexity of his students and that he wanted to get to know each of his students individually. He also realized just how much the day-to-day realities of his students affected their learning, positively 
Williams, T.K., McIntosh, R.W., \& Russell, W.B. Equity in Distance Education During COVID-19

for students of privilege and less so for students whose lives are more challenging. Chris realized that he needed to reassess the role of distance education and the opportunity that it presents. "I was actually really surprised to see some of my students who are troubled the most in the classroom, start thriving in the online environment" (Chris). The virtual school model may benefit more students than were previously utilizing it. For administrator Joy, COVID made her realize the critical role of human connection. She had to set her own tasks and concerns aside and provide more support to her teachers, students, and community. "I took on the task of calling some of our parents, you know, just checking on the students to find out why were they not logging in and some of the parents just wanted someone to just listen to them and listen to their frustration" (Joy).

\section{After COVID-19}

The educators in our focus group repeatedly stated that they do not want all the work they did to be in vain. First, if another lockdown were to occur, the teachers and administrators say there should be a plan. The COVID-19 experience should have taught lessons that should not have to be repeated. Second, students benefited from many of the changes the pandemic forced educators to make. Though many of the adjustments were intended to support high needs students, they provide for a better education for all students and should therefore continue post-COVID.

The participants stressed that one of the lessons they learned is that planning needs to deliberately and thoughtfully take into account the needs of the most vulnerable students. Chris strongly believes that we should do more for students with the highest needs, "the priority has to really be focused on the highest needs students, instead of providing families and students choice for the sake of choice." While he is worried that additional measures such as summer school and Saturday school may be perceived as a punishment by many, he emphasized that steps need to be taken to ensure those that the school district finds a way to provide support for students with the greatest need.

In order to make distance education sustainable now and after COVID, two things need to be addressed. The first is ongoing and explicit professional development for teachers. Educators often had to get the training they needed on their own time. Though it benefited 
Williams, T.K., McIntosh, R.W., \& Russell, W.B. Equity in Distance Education During COVID-19

them and their students, they were not compensated. To ensure that this necessary training can be applied across the board, educators, like Harmony, call for more funding: "We need more money in the budget so that we can provide...effective trainings." The second measure that needs to be addressed is straightforward and transparent communications from decisionmakers. According to Frank, this communication also needs to address the expectations about student performance and teacher performance. How are students, teachers, administrators, and schools going to be evaluated and held accountable? End-of-course and state testing can't keep getting pushed off or ignored; "we need to know where the kids are in their learning" (Chris). These concerns weigh on the participants.

Educators had to try new things in the COVID environment and discovered strategies that could support all students in any environment. Josh, for example, established an online school gaming club. The students come together online through Minecraft and he has found that it provides his online students to socialize. He doesn't want to see this end when COVID is over, "I hope those kinds of things aren't suddenly removed and say, okay, COVID is over, we're going to go ahead and stop all of those things that we put in place just in the meantime, as well" (Josh). They do not want to stop just because the crisis ends. Chris acknowledged that for many this is their first experience with distance learning and with experience the teachers and the students are getting better at it. Frank pointed out that the status quo from before COVID-19 wasn't working for all students, "we can't go back to normal, ever again because normal isn't going to be good enough" (Frank). While many students may still learn best in the traditional classroom environment, the participants don't want to see the options provided by distance education to simply go away.

\section{Discussion}

Our research focused on a series of questions regarding the impact of COVID-19 on education, including (a) how have teachers, schools, and districts responded? (b) did they consider the digital divide in their responses? (c) have teachers seen evidence of a digital divide? (d) do teachers feel that their technology preparation (or lack) impacted their and their students' experience? (e) will any changes or improvements be continued after COVID? Our results closely aligned with the themes that we have been able to identify in the review of the literature. The educators in our study also expressed their experiences dealing with the same 
Williams, T.K., McIntosh, R.W., \& Russell, W.B. Equity in Distance Education During COVID-19

issues reflected in the literature such as increased awareness of and urgency for addressing digital inequities (Reckoning and Awareness), The teachers, counselors, and administrators also highlighted the necessity for building community as was similarly found in existing literature (Connection and Community Building). Although they discussed both levels of the digital divide (Access and Efficacy), the educators in our study seemed to experience greater challenges with access due to technology failures and student connectivity problems. The themes that emerged from our focus group conversation demonstrated the educators' responses to and experiences with the digital divide. First, when educators put in extra work, students benefited. Second, the pandemic forced a shift in mindset that inspired new behaviors and resulted in positively surprising outcomes. Third, teachers want the lessons learned from the experience to lead to lasting change. These themes appear to focus on what the literature referred to as the digital divide's first level - access to technology.

We had expected to find that students and teachers were struggling to overcome the second level of the digital divide, the efficacy of technology use. We were surprised to find that the first level of the digital divide was far more common a complaint. Though the school district distributed laptops to help overcome the limitation of access, many families were restricted to only one device, even if those families had multiple students. Worse than limited access, many families were completely unreachable, with students unable to attend school because of closures and the schools having no reliable way to communicate with students and families. These students simply did not receive services or any instruction during closures and potentially beyond.

While our research doesn't differ greatly from the existing body of literature, it does add support to the current research of the impacts of COVID-19 on education. It shows that the available findings are not limited geographically to a single area or to a specific set of schools or districts. There are compelling arguments for further research into the impacts of COVID-19 on education, including but not limited to 1) identifying how much "slide" has occurred in student learning, 2) how many students have been lost from the system due to limited access and unreliable communication within the communities, 3) how are teacher 
Williams, T.K., McIntosh, R.W., \& Russell, W.B. Equity in Distance Education During COVID-19

education programs addressing digital education and preparing future teachers to cope with emergency remote learning.

Our research was conducted in good faith, but it relies on self-reported data in both the survey and focus group. The number of participants in the survey and the focus-group suggests a near-identical group of respondents though we cannot be sure because the survey was anonymous and there was a greater number of educators who agreed to participate than those who actually did participate in the study. Another limitation is the relatively brief interactions between research and participant. The research relies on a single survey and a single focus group. In future studies, it may be possible to broaden the survey participant base and to increase the number of focus groups or the number of times that the focus group interacts with the researchers.

\section{Conclusion and Implications}

Though we have certainly not exhausted the understanding of the impact of COVID-19 on educators or education based on the findings in one focus group discussion, the input of these educators is a necessary addition to the body of knowledge on this topic and the implications in this study are significant and should be considered for future research and practice. First, we learned that the digital divide is still a problem. We also learned that educators persevered and worked long hours beyond their contracts to overcome the challenges. It is important for educational researchers and leaders to explore funding sources to compensate educators fairly should the need arise again in the future. We also learned that educators are more than willing to get the necessary training to successfully implement new technologies to benefit their students. In fact, they want it. This training will require monetary support. Second, we learned new strategies for ensuring equitable educational outcomes and positive experiences in the classroom that should be applied beyond crisis situations. Teachers in this study witnessed the advantages of utilizing explicit instruction to support their students in person and at home. This was especially needed for students who were using the district online learning platform. Those students needed clarity, consistency, modeling, and support. The teachers, counselors, and administrators in the study learned the importance of community building. Effective community-building actions included those that connected the 
school and home environment, provided encouragement and support for students and parents, and allowed for flexibility. Creating community by collaboration and mutual support among teachers also benefited students. Decision-makers should pay attention to those lessons and include educators who served on the frontlines in any planning to inform educational policy decisions.

\section{References}

Anderson, M. (2020, June 23). Mobile Technology and Home Broadband 2019.

https://www.pewresearch.org/internet/2019/06/13/mobile-technology-and-homebroadband-2019/

Anderson, M., \& Kumar, M. (2020, May 30). Digital divide persists even as lower-income Americans make gains in tech adoption. https://www.pewresearch.org/facttank/2019/05/07/digital-divide-persists-even-as-lower-income-americans-make-gainsin-tech-adoption/

Bertacco, L. (2020). The four commonplaces: Teaching and learning in the time of COVID. Modern English Teacher, 29(3), 16-20. https://search.ebscohost.com/login.aspx?direct=true\&db=eue\&AN=144831073\&site= eds-live \&scope=site\&custid=current\&groupid=main\&authtype=shib

Creswell, J.W., \& Poth, C. N. (2018). Qualitative Inquiry \& Research Design: Choosing Among Five Approaches ( $4^{\text {th }}$ ed.). Sage.

Godsey, M. (2020). PREPARING FOR THE COVID SLIDE: The summer slide already presented its challenges. how can educators prepare for potentially steeper knowledge loss? Literacy Today (2411-7862), 38(1), 22-25. https://search.ebscohost.com/login.aspx?direct=true \&db=eue\&AN=144463196\&site= eds-live \&scope=site\&custid=current\&groupid=main\&authtype=shib

Hall, J., Roman, C., Jovel-Arias, C., \& Young, C. (2020). Pre-service teachers examine digital equity amidst schools' COVID-19 responses. Journal of Technology \& Teacher Education, 28(2), 435-442 
Williams, T.K., McIntosh, R.W., \& Russell, W.B. Equity in Distance Education During COVID-19

Hargittai, E. (2001). Second-level digital divide: Mapping differences in people's online skills. arXiv preprint cs/0109068.

Hargittai, E., \& Walejko, G. (2008). The participation divide: Content creation and sharing in the digital age. Information, Community and Society, 11(2), 239-256.

Kaden, U. (2020). COVID-19 school closure-related changes to the professional life of a K-12 teacher. Education Sciences, 10(6), 165. https://doi.org/10.3390/educsci10060165

Kalimullina, O., Tarman, B. \& Stepanova, I. (2021). Education in the Context of Digitalization and Culture: Evolution of the Teacher's Role, Pre-pandemic Overview. Journal of Ethnic and Cultural Studies, 8(1), 226-238. http://dx.doi.org/10.29333/ejecs/347

Kozleski, E. (2017). The uses of qualitative research: Powerful methods to inform evidencebased practice in education. Research and Practice for Persons with Severe Disabilities, 42(1), 19-32. https://doi.org/10.1177/1540796916683710

Lynch, M. (2020). E-learning during a global pandemic. Asian Journal of Distance Education, 15(1), 189-195. https://doi.org/10.1177/1540796916683710

Perrin, A. (2020, August 21). Digital gap between rural and nonrural America persists.

Retrieved October 18, 2020. https://www.pewresearch.org/facttank/2019/05/31/digital-gap-between-rural-and-nonrural-america-persists/

Peterson, L., Scharber, C., Thuesen, A., \& Baskin, K. (2020). A rapid response to COVID-19: one district's pivot from technology integration to distance learning. Information and Learning Sciences.

Pew Research Center. (2020, June 05). Demographics of Internet and Home Broadband Usage in the United States. https://www.pewresearch.org/internet/fact-sheet/internetbroadband/

Reinhart, J. M., Thomas, E., \& Toriskie, J. M. (2011). K-12 teachers: Technology use and the second level digital divide. Journal of Instructional Psychology, 38(3/4), 181.

Rhim, H. C., \& Han, H. (2020). Teaching online: foundational concepts of online learning and practical guidelines. Korean journal of medical education, 32(3), 175.

Sandvik, D. (2020). Lessons from locked-down learning. agora, 55(2), 12. 
Williams, T.K., Mclntosh, R.W., \& Russell, W.B. Equity in Distance Education During COVID-19

Sayer, P., \& Braun, D. (2020). The disparate impact of COVID - 19 remote learning on English learners in the United States. TESOL Journal, 11(3), e00546. https://doi.org/10.1002/tesj.546

Silverman, D. (2017). How was it for you? The interview society and the irresistible rise of the (poorly analyzed) interview. Qualitative Research, 17(2), 144-158. https://doi.org/10.1177/1468794116668231

Swarts, G. (2020). Re/coding Global Citizenship: How Information and Communication Technologies have Altered Humanity... and Created New Questions for Global Citizenship Education. Research in Social Sciences and Technology, 5(1), 70-85. https://doi.org/10.46303/ressat.05.01.4

Tadeu, P., Fernandez Batanero, J., \& Tarman, B. (2019). ICT in a Global World. Research in Social Sciences and Technology, 4(2), i-ii. https://doi.org/10.46303/ressat.04.02.ed Tang, H., \& Bao, Y. (2020). Social Justice and K-12 Teachers' Effective Use of OER: A CrossCultural Comparison by Nations. Journal of Interactive Media in Education, 2020(1).

Trust, T., \& Whalen, J. (2020). Should Teachers be Trained in Emergency Remote Teaching? Lessons Learned from the COVID-19 Pandemic. Journal of Technology \& Teacher Education, 28(2), 189-199.

Whittle, C., Tiwari, S., Yan, S., \& Williams, J. (2020). Emergency remote teaching environment: A conceptual framework for responsive online teaching in crises. Information and Learning Sciences, 121(5), 311-319. https://www.emerald.com/insight/content/doi/10.1108/ILS-04-2020-0099/full/html 


\section{Appendix A}

\section{Distance Learning Equity Survey}

Demographic Information (Participants selected from a drop-down menu.)

Gender

Age

Race/ Ethnicity

District

Title I Status

Racial Make-up of Students

Socioeconomic Status of Students

Position

Grade Level Taught

Subject Taught

Perception Questions (For Likert-type scale, participants rated their levels of agreement with the provided statements.)

Section 1: How have teachers, schools and districts responded?

- My district/school did everything possible to make sure that all students had access to learning devices and software to succeed.

- My district/school did everything possible to make sure that all students had the technology training to succeed.

- My district/school did everything possible to make sure that teachers and staff had the training necessary to effectively facilitate learning.

- I was supported by my district/school.

- I did all I could to support all my students?

- I did all I could to support my coworkers?

Open-ended: Describe your experience during the initial COVID lockdown. 
Section 2: Did they consider the digital divide in their response?

- There was a special distribution of resources to support high needs populations (students with disabilities, students living in poverty, students from marginalized communities, students from minoritized communities).

- There was training for students from high need populations.

- There was training for parents of students from high needs populations.

- If there was training for high needs populations, my district/school made sure that the students and families were well aware of opportunities for training.

- I did everything possible to communicate with my students and families from high needs populations.

Open-ended: How did you and/or your district/school address the disparate impact of COVID-19 on students from high needs populations?

Section 3: Have teachers seen evidence of a digital divide?

- My students from high needs populations suffered a greater impact on their learning than other students.

- It was more difficult for me to maintain communication with my students from high needs populations.

- My students from high needs populations were more likely to lack technological resources needed to continue learning.

- My students from high needs populations were more likely to lack the technological skills necessary to continue learning.

Open-ended: What differences did you notice between your students from high needs populations and other students?

Section 4: Do teachers feel that their technology preparation (or lack) impacted their and their students' experience?

- I already had the necessary technological preparation to facilitate learning for my students when distance learning started.

- Additional training was provided for me during initial distance learning. 
- I had to find my own training in order to ensure continuity of learning for my students.

- My students suffered due to my lack of technological skills.

- My students benefited from my technological skills.

Open-ended: How did your technological preparation (or lack thereof) impact your experience and/or your students' experience? 


\section{Appendix B}

\section{Focus Group Discussion Questions}

1. What kinds of training has been most helpful for you?

2. How are you overcoming technical issues students have such as no connection, WebEx issues, etc.?

3. What is working as far as communication with families?

4. How are you overcoming the issues involving parent/grandparent extra support needs?

5. What is working to help online students stay on track and engaged?

6. What kinds of activities work best for online students?

7. What did you learn from the COVID experience that you could apply to benefit students going forward post-COVID?

8. Have you seen any benefits or improvements due to COVID-19?

9. What changes need to be made for this to be sustainable (next semester and beyond)?

10. What has helped you most to be successful in doing your job?

11. If there were to be another lockdown, what is the most important thing you would you want educational decision-makers to provide for you or the students?

12. What are you doing to strike a work/life balance? How are you attending to your mental health? 